ORIGINAL ARTICLE

\title{
The interaction between caveolin-1 and Rho-GTPases promotes metastasis by controlling the expression of alpha5-integrin and the activation of Src, Ras and Erk
}

\author{
E Arpaia ${ }^{1,2,6}$, H Blaser ${ }^{1,6}$, M Quintela-Fandino ${ }^{1,3,6}$, G Duncan ${ }^{1}$, HS Leong ${ }^{4}$, A Ablack ${ }^{4}$, \\ SC Nambiar ${ }^{4}$, EF Lind ${ }^{1}$, J Silvester ${ }^{1}$, CK Fleming ${ }^{1}$, A Rufini ${ }^{1,5}$, MW Tusche ${ }^{1}$, A Brüstle ${ }^{1}$, \\ PS Ohashi ${ }^{1,2}$, JD Lewis ${ }^{4}$ and TW Mak ${ }^{1,2}$

\begin{abstract}
${ }^{1}$ The Campbell Family Institute for Breast Cancer Research, University Health Network, Toronto, Ontario, Canada; ${ }^{2}$ Departments of Medical Biophysics and Immunology, University of Toronto, Toronto, Ontario, Canada; ${ }^{3}$ Spain/Spanish National Cancer Centre (CNIO), Clinical Investigation Unit, Breast Cancer Group C/Melchor Fernandez Almagro-3, Madrid, Spain; ${ }^{4}$ Translational Prostate Cancer Research Group, London Regional Cancer Program, London, Ontario, Canada and ${ }_{5}^{5}$ Laboratory of Apoptosis in Cancer, MRC Toxicology Unit, Hodgkin Building, University of Leicester, Lancaster, UK
\end{abstract}

Proteins containing a caveolin-binding domain (CBD), such as the Rho-GTPases, can interact with caveolin-1 (Cav1) through its caveolin scaffold domain. RhoGTPases are important regulators of $\mathrm{p} 130^{\mathrm{Cas}}$, which is crucial for both normal cell migration and Src kinasemediated metastasis of cancer cells. However, although Rho-GTPases (particularly RhoC) and Cav1 have been linked to cancer progression and metastasis, the underlying molecular mechanisms are largely unknown. To investigate the function of Cav1-Rho-GTPase interaction in metastasis, we disrupted Cav1-Rho-GTPase binding in melanoma and mammary epithelial tumor cells by overexpressing $\mathrm{CBD}$, and examined the loss-of-function of RhoC in metastatic cancer cells. Cancer cells overexpressing CBD or lacking RhoC had reduced p130 Cas phosphorylation and Rac1 activation, resulting in an inhibition of migration and invasion in vitro. The activity of Src and the activation of its downstream targets FAK, Pyk2, Ras and extracellular signal-regulated kinase (Erk)1/2 were also impaired. A reduction in $\alpha 5$-integrin expression, which is required for binding to fibronectin and thus cell migration and survival, was observed in CBD-expressing cells and cells lacking RhoC. As a result of these defects, CBD-expressing melanoma cells had a reduced ability to metastasize in recipient mice, and impaired extravasation and survival in secondary sites in chicken embryos. Our data indicate that interaction between Cav1 and Rho-GTPases (most likely RhoC but not RhoA) promotes metastasis by stimulating $\alpha 5$-integrin expression and regulating the Src-dependent activation of p130 $^{\text {Cas }} /$ Rac1, FAK/Pyk2 and Ras/Erk1/2 signaling cascades.

Oncogene (2012) 31, 884-896; doi:10.1038/onc.2011.288; published online 18 July 2011

Correspondence: Professor TW Mak, Campbell Family Institute for Breast Cancer Research, University Health Network, 620 University Avenue, Suite 706, Toronto, Ontario, Canada M5G 2M9.

E-mail: tmak@uhnresearch.ca

${ }^{6}$ These authors contributed equally to this work.

Received 3 March 2010; revised and accepted 6 June 2011; published online 18 July 2011
Keywords: Rho-GTPase; caveolin-1; alpha5-integrin; Src; cancer; intravital microscopy

\section{Introduction}

The scaffold protein p130 cas, Rho-GTPases and caveolin-1 (Cav1) are among the key signaling molecules mediating actin cytoskeleton remodeling (Hall 1998; Meenderink et al., 2010; Fecchi et al., 2011). This remodeling depends on Racl activation, which is controlled by phosphorylated p130 ${ }^{\text {as }}$ (Marti et al., 1997; Ohta et al., 1999; Brabek et al., 2005). Phosphorylation of $\mathrm{p} 130^{\mathrm{Cas}}$ is thus a pivotal step in cell movement and metastasis. In normal and cancer cells, p130 ${ }^{\text {Cas }}$ is phosphorylated by Src kinase, thus Src also regulates the cytoskeleton (Sakai et al., 1994). Src-mediated p130 ${ }^{\text {Cas }}$ phosphorylation drives Racl activation at the cell's leading edge (Timpson et al., 2001; Sharma and Mayer 2008), thereby promoting cell motility.

Rho-GTPases have been linked to cancer cell migration/invasion, and elevated levels of RhoC have been frequently associated with metastasis (Sahai and Marshall 2002; Narumiya et al., 2009). Our previous work showed that $\mathrm{RhoC}^{+/-}$PyMT and $\mathrm{RhoC}^{-/-}$PyMT mice develop primary tumors at the same frequency but $\mathrm{RhoC}^{-/-} \mathrm{PyMT}$ mice exhibit significantly fewer metastatic lesions in the lungs (Hakem et al., 2005). In vitro, mammary tumor cells from $\mathrm{RhoC}^{-/-}$PyMT animals show greatly impaired migration/invasion abilities. However, the underlying mechanism by which RhoC functions in metastasis is largely unknown. At the molecular level, small RhoGTPases are required not only for cytoskeletal remodeling but also for Ras-induced transformation (Yamamoto et al., 1999; Jaffe and Hall 2002). Ras activates various downstream mediators important for cell migration, proliferation and survival (Bonni et al., 1999; Yip et al., 2007). Rho-GTPases are also linked to integrins, which are critical for cell adhesion, migration and survival. 
Inhibition of integrin signaling in melanoma cells suppresses the Rho/ROCK pathway, thus blocking cell invasion and metastasis (Kidera et al., 2010).

The scaffold protein Cavl appears to act either as a tumor suppressor or as an oncogene but its precise role in metastasis remains unclear (Goetz et al., 2008; Quest et al., 2008). Although $\mathrm{Cav1}^{-1-}$ mice do not develop spontaneous tumors, these animals did develop malignancies when either treated with a carcinogen (Capozza et al., 2003) or crossed with a tumor-prone strain such as the MMTV-PyMT (mouse mammary tumor viruspolyoma middle-T antigen) mouse (Williams et al., 2003, 2004). On the other hand, the TRAMP mouse model (transgenic adenocarcinoma of mouse prostate), which develops spontaneous prostate carcinomas, exhibited greatly reduced metastatic spread when Cav1 was genetically deleted (Williams et al., 2005). In tumor-prone mice, loss of Cavl gene expression dramatically accelerated the development of multifocal dysplastic mammary lesions (Williams et al., 2003). However, increased Cav1 expression correlated with metastasis in later neoplastic stages during hepatocellular carcinogenesis (Cokakli et al., 2009). Also, increased Cav1 expression have been observed in melanoma, lung adenocarcinoma, prostate cancer and renal cell carcinoma in humans (Thompson et al., 1999; Li et al., 2001; Ho et al., 2002; Campbell et al., 2008; Felicetti et al., 2009). These conflicting observations highlight the lack of understanding of the diverse biological role of Cav1 in cancer.

At the biochemical level, Cav1 co-fractionates with many signaling molecules, including Rho-GTPases (Smart et al., 1999; Couet et al., 2001). Rho-GTPases bind to Cav1 through their caveolin-binding domains (CBDs) (Couet et al., 1997). In vitro, an isolated CBD peptide derived from a G-protein was shown to interact directly with the caveolin scaffold domain of Cav1 and competitively inhibits the binding of the G-protein to Cav1 (Couet et al., 1997). This makes the CBD a useful tool for examining the effects of disrupting the Cav1-Rho-GTPase interaction on cell migration, invasion and metastasis.

In this study, we show that the disruption of Cav1Rho-GTPase interaction prevents the activation of Rac1 mediated by Src-dependent $\mathrm{p} 130^{\mathrm{Cas}}$ phosphorylation, as well as Src-dependent activation of Ras and extracellular signal-regulated kinase (Erk)1/2. Importantly, we demonstrate that Cav1-Rho-GTPase interaction is crucial for $\alpha 5$-integrin expression. In vivo, reducing the interaction of Cav1 with Rho-GTPases results in decreased extravasation and reduced survival of metastatic cells. Our data implicate the Cav1-mediated control of Rho-GTPase signaling as an important mechanism promoting metastasis.

\section{Results}

Cav1-Rho-GTPase interaction regulates p130 cas phosphorylation

Various clones of the B16 melanoma cell line exhibit diverse metastatic potential and express different levels of RhoC. The B16 F10 clone is the most invasive and shows higher levels of RhoC and phosphorylated p130 Cas (ph-p130 ${ }^{\text {Cas }}$ ) than the weakly invasive F0 clone (Clark et al., 2000). We assessed the levels of Cav1 expression in F0, F1 and F10 B16 clones, and evaluated the Srcdependent phosphorylation of p130 Cas at Y410 and Y165. Both Cavl protein and ph-p130 Cas levels were increased in F1 and F10 cells compared with F0 cells (Figure 1a). To determine whether Cav1 was required for p130 Cas phosphorylation, we silenced Cav1 expression in F10 cells and found that Cav1 indeed regulates p130 ${ }^{\text {Cas }}$ phosphorylation (Figure 1b). To define RhoC's role in p130 ${ }^{\text {Cas }}$ phosphorylation, we generated stable F10 clones expressing small interfering RNA (siRNA) or short hairpin RNA against RhoC (siRhoC, shRhoC). These cells also exhibited lower levels of ph-p130 Cas but Cav1 expression was not altered (Figure 1c). To determine if this effect held true in other tumor cells, we established a cancer cell-line (designated as PyMT) from explanted MMTV-PyMT mammary epithelial tumor cells. RhoC knockdown in PyMT cells also decreased ph-p130 ${ }^{\mathrm{Cas}}$ without affecting Cav1 (Figure 1c). Notably, the knockdown of RhoA did not affect ph-p130 ${ }^{\text {Cas }}$ levels (Supplementary Figure S1a). These data show that both Cav1 and RhoC regulate ph-p130 Cas in cancer cells, and that RhoC's function in this context cannot be compensated for by other Rho-GTPases.

To explore whether Cav1-Rho-GTPase interaction was important for $\mathrm{p} 130^{\mathrm{Cas}}$ phosphorylation, we exploited the fact that the presence of the isolated CBD (Supplementary Figures S1b and c) can inhibit Cav1-Rho-GTPase interaction (Couet et al., 1997). We generated F10 cells stably overexpressing the wild-type $\mathrm{CBD}\left(\mathrm{CBD}^{\mathrm{wt}}\right)$ or a non-functional mutant form of CBD (CBD ${ }^{\mathrm{mut}}$ ) (Supplementary Figure S1c). We then assessed the ability of $\mathrm{CBD}^{\text {wt }}$ to inhibit Cav1-Rho-GTPase interaction by pulling down GTPases with GST-Rhoteckin-RBD, followed by immunoblotting for Cav1. In CBD ${ }^{\text {wt }}$-expressing cells, we found that considerably less Cav1 was bound to active

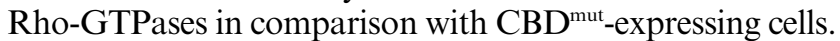
This indicated that the $\mathrm{CBD}^{\mathrm{wt}}$ indeed disrupts the Cav1Rho-GTPase interaction (Figure 1d). To evaluate the functional consequences of $\mathrm{CBD}^{\mathrm{wt}}$ expression, we expressed either $\mathrm{CBD}^{\mathrm{wt}}$ or $\mathrm{CBD}^{\mathrm{mut}}$ in-frame with green fluorescent protein (GFP) (Supplementary Figure S1c) in F10 cells. Cells expressing CBD ${ }^{\text {wt }}$ GFP showed reduced ph-p130 Cas similar to cells expressing $\mathrm{CBD}^{\mathrm{wt}}$ alone, whereas

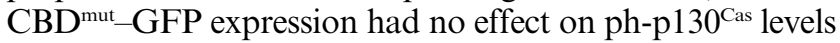
(Figure 1e, Supplementary Figure S1d). Thus, the inhibition of Cav1-Rho-GTPase interaction by $\mathrm{CBD}^{\mathrm{wt}}$ had the same effect on ph-p130 as as the lack of Cav1 or RhoC expression. These results indicate that the interaction of Cav1 with Rho-GTPases is critical for normal p130 cas phosphorylation. As the lack of Cavl or RhoC alone almost completely abolished p130 cas phosphorylation, we consider RhoC as the main GTPase that binds to Cav1 and elicits p130 ${ }^{\text {Cas }}$ signaling in metastatic tumor cells.

\section{Cav1-Rho-GTPase interaction is required for cellular migration/invasion}

Activation of Rac1 is important for both migration and cytoskeletal remodeling in many different cell types and 


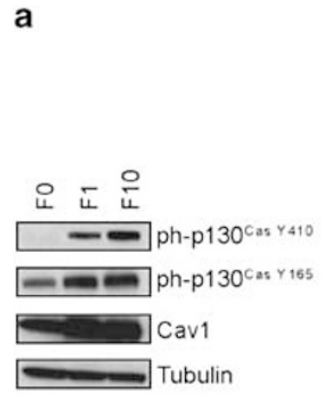

b

d

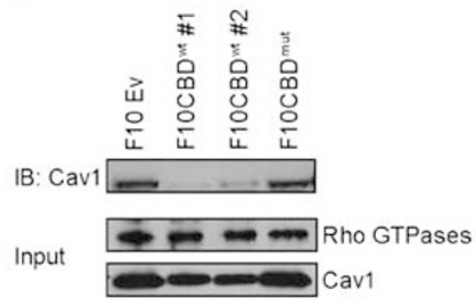

C
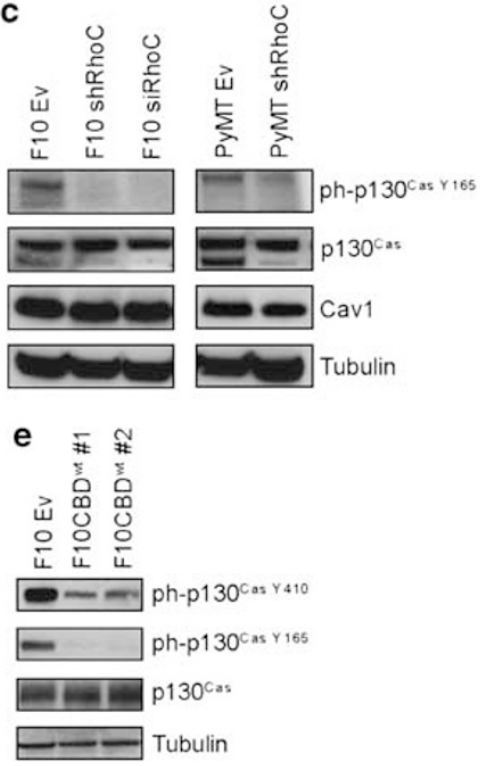

Figure 1 RhoC and Cav1 regulate p130 Cas phosphorylation. (a) Correlation between Cav1 and ph-p130 Cas. The indicated clones of B16 melanoma cells were evaluated by immunoblotting (IB) for levels of Cav1 and p130 (b) Transient silencing (two independent clones \#1, \#2) of Cav1 expression reduces p130 ${ }^{\mathrm{Cas} Y 410}$ phosphorylation. (c) RhoC controls php130 ${ }^{\text {Cas }}$ levels. F10 cells stably expressing siRhoC or shRhoC were analyzed by IB to detect ph-p130 ${ }^{\text {Cas }}$ and Cav1. The ph-p130 ${ }^{\text {Cas }}$ levels are also reduced in PyMT cells expressing shRhoC. (d) CBD ${ }^{\mathrm{wt}}$ inhibits the binding of Rho-GTPases to Cavl. Active Rho-GTPases were pulled-down with agarose beads GST-Rhoteckin-RBD-conjugated (RBD: Rho Binding Domain) and Cavl was detected by IB. (e) $\mathrm{CBD}^{\mathrm{wt}}$ expression reduces ph-p130 ${ }^{\mathrm{Cas}}$. The levels of $\mathrm{p} 130^{\mathrm{Cas}}$ and $\mathrm{p} 130^{\mathrm{Cas}}$ phosphorylated at Y410 or Y165 were assessed by IB in F10Ev (control F10 cells expressing empty vector) and two independent clones of F10 cells overexpressing CBD ${ }^{\mathrm{wt}}\left(\mathrm{F} 10 \mathrm{CBD}{ }^{\mathrm{wt}} \# 1\right.$, \#2).

depends on ph-p130 Cas (Klemke et al., 1998; Heasman and Ridley 2008). We therefore assessed the effects of $\mathrm{CBD}^{\mathrm{wt}}$ expression or RhoC depletion on Rac1 activation, actin cytoskeleton organization and migration/ invasion in vitro. We assayed the levels of active (GTPbound) Racl in F10 cells expressing the control empty vector (Ev), $\mathrm{CBD}^{\mathrm{wt}}, \mathrm{CBD}^{\mathrm{mut}}$ or siRhoC, we found that active Racl was dramatically reduced in F10CBD ${ }^{\mathrm{wt}}$ and F10siRhoC cells compared with F10CBD ${ }^{\text {mut }}$ and F10Ev cells (Figure 2a). Consistent with the loss of Rac1 activation, rhodamine-phalloidin staining revealed that the actin cytoskeleton of F10CBD ${ }^{\text {wt }}$ cells was clearly altered compared with F10Ev cells (Figure 2b). The $\mathrm{CBD}^{\mathrm{wt}}$-expressing cells displayed reduced F-actin stress fibers but abundant fragmented F-actin (puncta) characteristic of defects in actin polymerization or stability. This finding suggested that, in the absence of Cav1Rho-GTPase interaction, tumor cells might not be able to sufficiently remodel their cytoskeletons to permit migration/invasion. Indeed, F10CBD ${ }^{\text {wt }}$ and F10siRhoC cells both exhibited severely impaired migration as well as invasion (Figures 2c and d and Supplementary Figure S2). These data show that cells in which Cav1-Rho-GTPase interaction is disrupted exhibit reduced Racl activation that is associated with defective cytoskeletal remodeling and reduced migration/invasion capacity.

\section{Cav1-Rho-GTPase interaction and RhoC are important for Src, Ras and Erk activation}

Elevated Src expression is usually associated with increased metastatic capability (Wheeler et al., 2009).
As our earlier results showed that Cav1 controls p130 ${ }^{\mathrm{Cas}}$ phosphorylation (Figure 1b), and Src kinase is known to phosphorylate p130 Cas (Sakai et al., 1994), we evaluated the impact of loss of Cav1 expression on Src activation. F10shCav1 cells showed a significant impairment of SrcY416 phosphorylation compared with F10Ev cells (Figure 3a). As RhoC depletion had a strong effect on ph-p130 Cas levels (Figure 1c), we examined Src activation in F10siRhoC and PyMTshRhoC cells and found that RhoC expression was indeed crucial for Src activation in both cell lines (Figure 3b). These data are consistent with previous reports showing that various RhoGTPases are involved in recruiting Src to the plasma membrane, and that this event may be important for Src activation (Fincham et al., 1996; Timpson et al., 2001; Yamana et al., 2006). Importantly, depletion of RhoC alone was sufficient to almost completely abolish Src activation in metastatic cancer cells.

We next assessed whether $\mathrm{CBD}^{\mathrm{wt}}$-mediated disruption of Cav1-Rho-GTPase interaction could prevent Src activation. F10CBD ${ }^{\text {wt }}$ cells did show a decrease in Src activation, although to a lesser extent than in cells lacking Cav1 or RhoC (Figure 3c). Furthermore, consistent with the decreased Src activation in F10CBD ${ }^{\text {wt }}$ cells, the levels of activated FAK and Pyk2, two direct downstream targets of Src, were reduced upon RhoC knockdown or $\mathrm{CBD}^{\mathrm{wt}}$ expression (Figure 3c). Importantly, the expression in F10 cells of a dominant-negative form of Src (Src-DNRF) showed the same suppressive effect on FAK and Pyk 2 phosphorylation. As FAK and Pyk2 are involved in cell migration/invasion and adhesion (Ilic et al., 1995; Sieg et al., 1998; Schaller 2010), the altered 

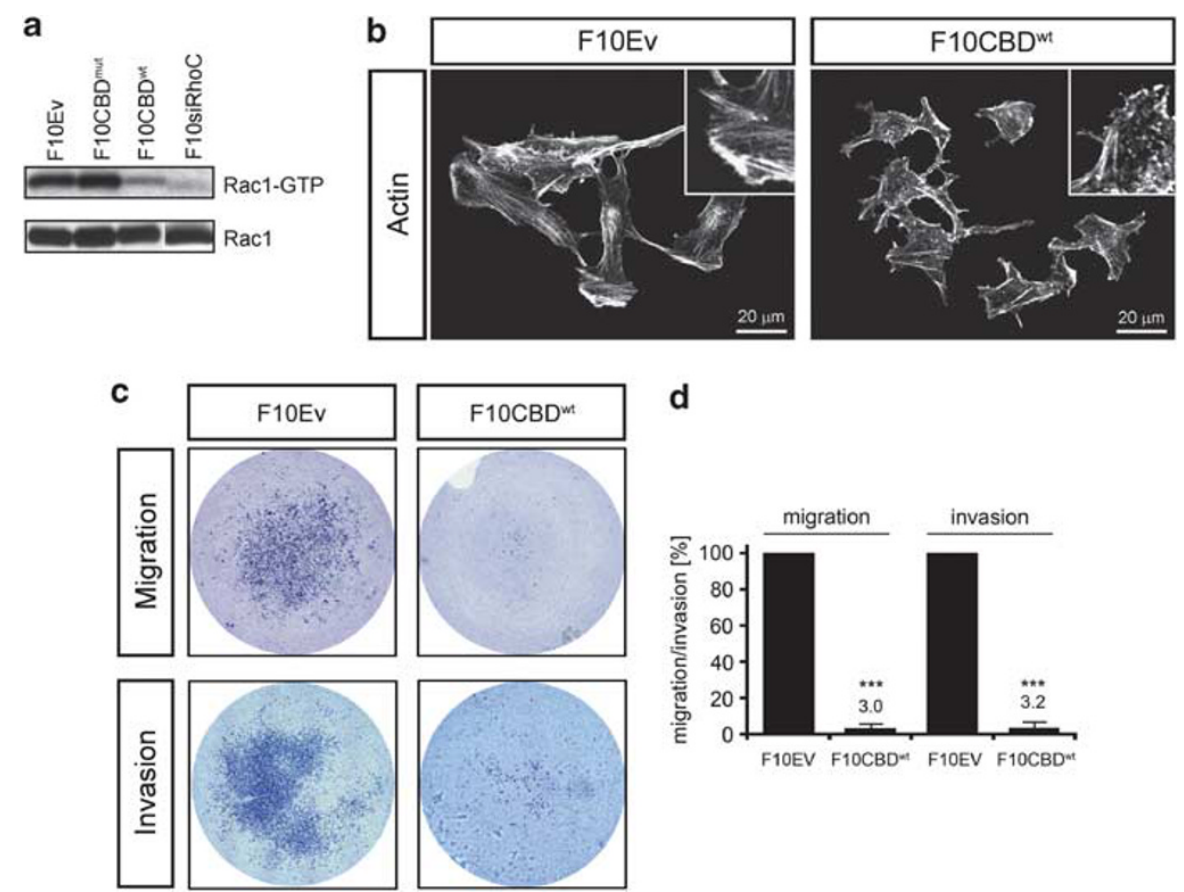

d
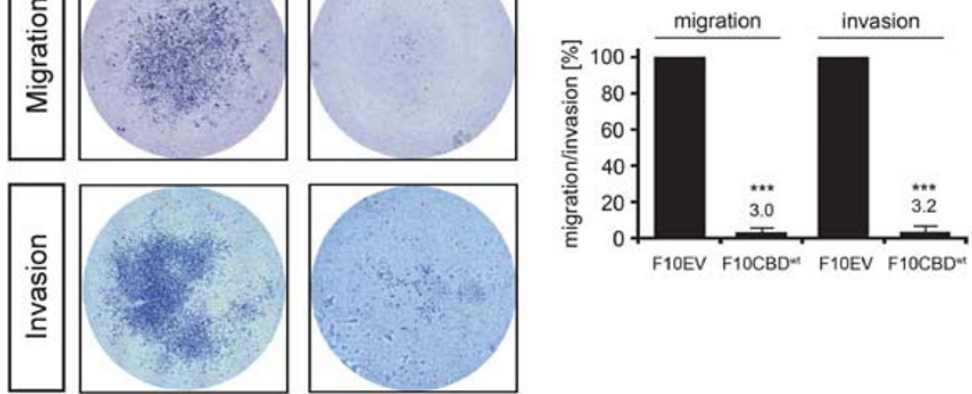

Figure 2 Effects of disrupting the Cav1-Rho-GTPase interaction. (a) Decreased Rac1 activation in the presence of CBD ${ }^{\mathrm{wt}}$ or absence of RhoC. Active Rac1 (Rac1-GTP) was pulled down with GST-PAK-PDB-conjugated agarose beads (PAK: p21-activated kinase 1; PDB: p21-binding domain) from extracts of F10 cells expressing Ev, CBD ${ }^{\text {mut }}$, CBD ${ }^{\mathrm{wt}}$, siRhoC. Racl was detected by IB. (b) CDB ${ }^{\mathrm{wt}}$ expression alters cytoskeletal remodeling. Rhodamine-phalloidin stainings of F10CBD ${ }^{\text {wt }}$ cells show abundant F-actin fragments and reduced F-actin stress fibers compared with F10Ev cells. Insets, 2.5-fold magnification of a representative cell area. $(\mathbf{c}, \mathbf{d}) \mathrm{CBD}$ wt expression impairs migration/invasion. Top: F10Ev cells are able to migrate on collagen IV-coated filters; F10CBD ${ }^{\mathrm{wt}}$ cells are unable to do so. Bottom: F10CBD ${ }^{\text {wt }}$ cells show severe impairment to invade Matrigel. Quantification was performed by using ImagePro software (Media Cybernetics, Inc., Bethesda, MD, USA) - 'filter-area' occupied by cells is presented in percentage of migration/invasion, $* * *=$ statistically significant (two-tailed $t$-test with s.e.m.), $P<0.001$.

regulation of Rac1, Src, FAK/Pyk2 that follows the disruption of Cav1-Rho-GTPase interaction or the reduction of RhoC expression explains the defects in migration/invasion observed in vitro.

Erk1/2 activation downstream of Src promotes cancer cell migration/invasion (Krueger et al., 2001). To determine whether RhoC depletion or $\mathrm{CBD}^{\mathrm{wt}}$ expression affected Erk $1 / 2$ activation, we assayed phospho-Erk1/2 levels in F10 $\mathrm{CBD}^{\mathrm{wt}}$ and F10siRhoC cells. Erk1/2 activation was drastically reduced in the absence of $\mathrm{RhoC}$ or in the presence of the $\mathrm{CBD}^{\mathrm{wt}}$, to an even greater extent than in F10SrcDNRF cells (Figure 3d). Src acts through Ras to elicit Erk1/2 activation (Gardner et al., 1993), and a large body of evidence indicates that Ras is intimately associated with integrin function required for cell adhesion, migration and growth (Zhang et al., 1996; Kinbara et al., 2003). Therefore, we first assayed Ras activation in F10CBD ${ }^{\mathrm{wt}}$ and F10shRhoC cells and found that disruption of Cav1-Rho-GTPase interaction, or RhoC silencing, markedly reduced the levels of Ras-GTP (Figure 3e). Next, we examined $\alpha 5$-integrin expression in F10CBD ${ }^{\mathrm{wt}}, \mathrm{F} 10 \mathrm{CBD}^{\mathrm{mut}}$, F10shRhoC and F10shRhoA. We found that control F10 cells expressed high levels of $\alpha 5$-integrin, a marker that correlates with a highly malignant phenotype in melanoma (Natali et al., 1995; Keely et al., 1998). We detected similar levels of $\alpha 5$-integrin in $\mathrm{F} 10 \mathrm{CBD}^{\mathrm{mut}}$ cells but found a drastic reduction of $\alpha 5$-integrin expression in $\mathrm{CBD}^{\mathrm{wt}}$-expressing cells and in shRhoC cells (Figure 3f). Remarkably, F10shRhoA cells showed only a slight reduction on $\alpha 5$ integrin expression. The $\alpha 6$-integrin and $\beta 1$-integrin expression was not affected (data not shown). To further characterize the $\alpha 5$-integrin expression, we assessed the effects of the expression of $\mathrm{CBD}^{\mathrm{wt}}$, shRhoC and shRhoA on $\alpha 5$-integrin mRNA levels. We found that only the $\mathrm{CBD}^{\mathrm{wt}}$ or shRhoC expression profoundly reduced the mRNA levels of $\alpha 5$-integrin (Figure $3 \mathrm{~g}$ ). Notably, the expression of $\mathrm{CBD}^{\mathrm{wt}}$ had no negative impact on RhoC expression. The reduced expression of $\alpha 5$-integrin in cells expressing $\mathrm{CBD}^{\mathrm{wt}}$ or shRhoC is consistent with their inability to metastasize.

Taken together, our results suggest that Cav1-RhoGTPase interaction is important not only for Src, Ras and Erk1/2 activation but also for $\alpha 5$-integrin expression required for cancer cell migration/invasion. As the reduction of $\mathrm{RhoC}$ has a major impact on these molecules, we believe that RhoC is the main GTPase contributing to the migratory and invasive properties of melanoma cells.

\section{Disruption of Cav1-Rho-GTPase interaction reduces} metastasis in mice

Erk $1 / 2$ have roles in cell motility but these molecules are also crucial for cancer cell proliferation and survival (Dent et al., 1999; Shaul and Seger 2007; Mebratu and 
Tesfaigzi 2009). As $\mathrm{CBD}^{\mathrm{wt}}$ expression reduced Erk1/2 activation (Figure 3d), we assessed whether CBD ${ }^{\text {wt }}$ expression could alter the metastatic potential of cancer cells in vivo. Luciferase-expressing F10Ev, F10CBD ${ }^{\mathrm{wt}}$ and $\mathrm{F} 10 \mathrm{CBD}{ }^{\text {mut }}$ cell lines were tail-vein injected into C57/B6 mice, and monitored for metastasis and survival. Non-transfected F10 cells and F10Ev cells had metastasized by 2 weeks post-injection (Figure 4a, top). Similarly, mice injected with F10CBD ${ }^{\text {mut }}$ cells also showed extensive metastasis (Figure 4a, middle). How- ever, mice injected with F10CBD ${ }^{\text {wt }}$ cells did not develop lung tumors until 3 weeks post-injection, and no significant spread of cancer cells was observed until 4 weeks post-injection (Figure $4 \mathrm{a}$, bottom). As a consequence, mice injected with $\mathrm{F} 10 \mathrm{CBD}^{\mathrm{wt}}$ cells had a lifespan that was double that of mice injected with either F10Ev or F10CBD ${ }^{\text {mut }}$ cells (Figure $4 \mathrm{~b}$ ). Comparable results were obtained when these studies were repeated using female mice (Supplementary Figure S3). In line with our earlier results (Figures 3c and d), SrcDNRF expression also a

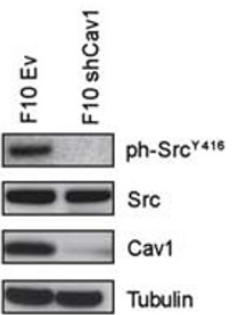

b

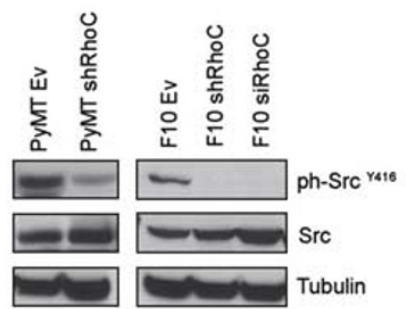

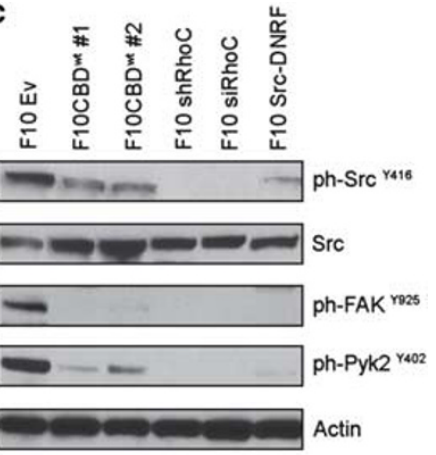

e

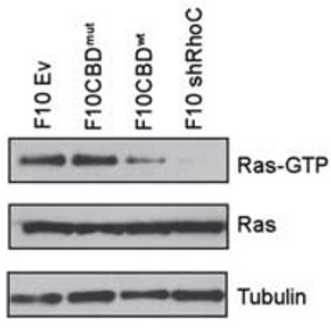

d

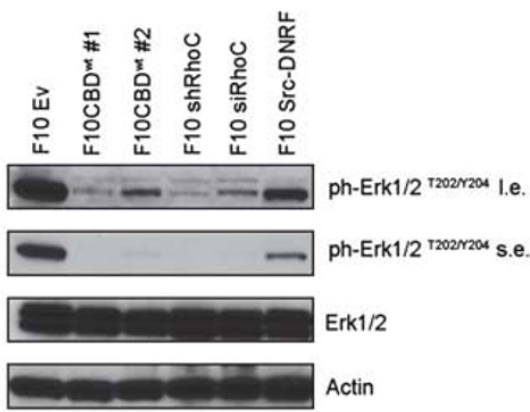

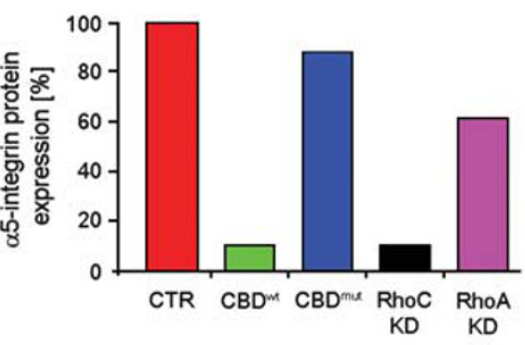

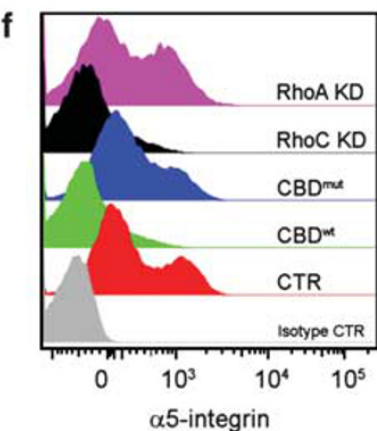

$\alpha 5$-integrin

g

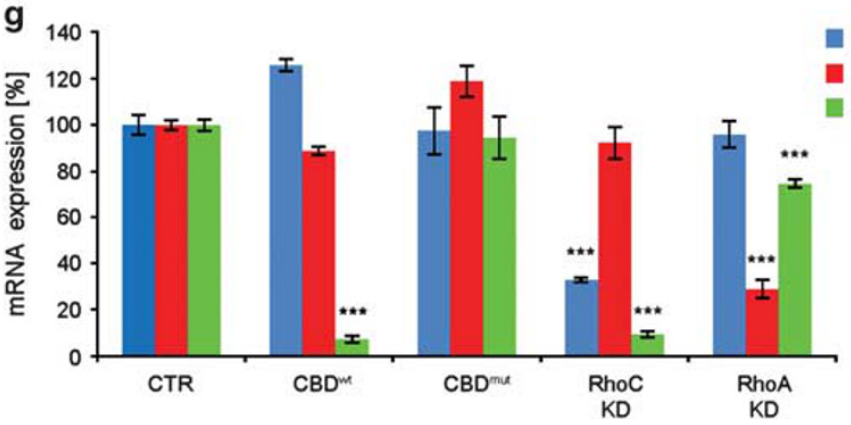


greatly diminished the aggressiveness of the injected F10 cells and prolonged mouse lifespan (Figure 4c). Similar results were obtained when luciferase-expressing PyMT-CBD ${ }^{\text {wt }}$ or PyMT-Ev cells were injected into the tail veins of SCID mice. Whereas PyMT-Ev cells readily established tumors in the lungs, PyMT-CBD ${ }^{\mathrm{wt}}$ cells failed to do so (Figure 5a). As a consequence, mice that received PyMT-CBD ${ }^{\mathrm{wt}}$ cells lived much longer than animals injected with PyMT-Ev cells (Figure 5b). PyMT cells expressing SrcDNRF were also less metastatic
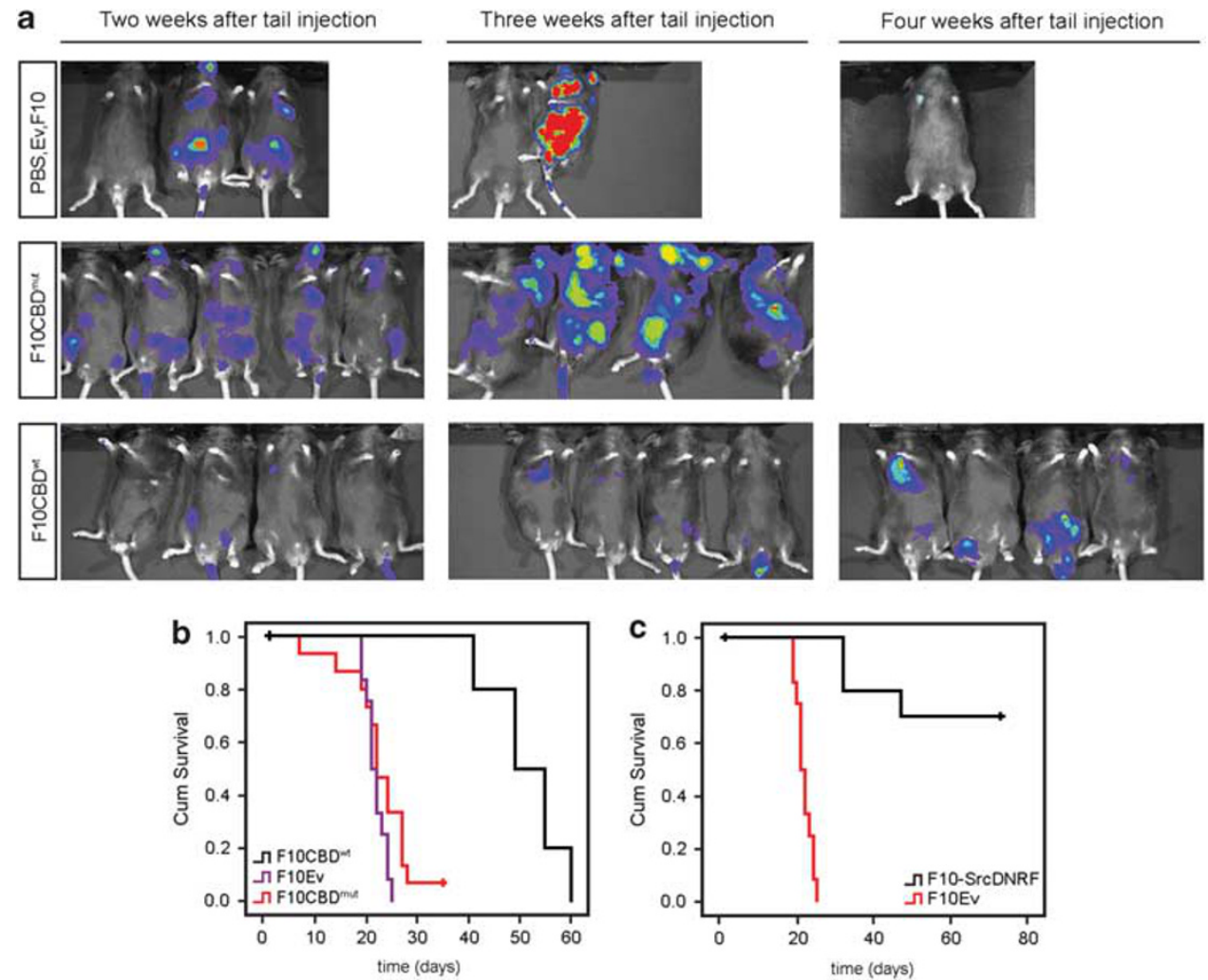

Figure 4 Disruption of the Cav1-Rho-GTPase interaction in F10 cells: in vivo effects. (a) CBD ${ }^{\text {wt }}$ expression reduces metastasis. Top panel, controls. Male C57/B6 mice were grafted with: PBS containing no cells (left), F10Ev cells (middle) or naive F10 cells (right). Middle and bottom panels, male mice were tail-vein injected with F10CBD ${ }^{\mathrm{mut}}$ or F10CBD ${ }^{\mathrm{wt}}$ cells, respectively. Mice were imaged at the indicated time points post-injection using a Xenogen apparatus (Caliper Life Sciences (Corporate Headquarters), Hopkinton, MA, USA). (b) Extended lifespan of mice tail-vein injected with F10CBD ${ }^{\mathrm{wt}}$ cells. The survival of the indicated mice from (a) was examined using Kaplan Meier plots. Median overall survival: F10Ev, 21.75 days $\left(n=6\right.$ mice); F10CBD ${ }^{\text {mut }}, 22.6$ days $\left(n=10\right.$ mice); F10CBD ${ }^{\text {wt }}$, 51.4 days $\left(n=10\right.$ mice). Log-rank test: F10Ev vs F10CBD ${ }^{\text {wt }}, P<0.001 ; F_{10 C B D}{ }^{\text {mut }}$ vs F10CBD ${ }^{\text {wt }}, P<0.001 ;$ F10Ev vs F10CBD $^{\text {mut }}$, $P=0.106$. (c) Kaplan-Meier survival plots for C57/B6 mice tail-vein injected with F10Ev or F10SrcDNRF cells. Median overall survival: F10Ev, 21.75 days $(n=10$ mice); F10SrcDNRF, 62.2 days $(n=10$ mice). Log-rank test, $P<0.001$.

Figure 3 Cav1-Rho-GTPase interaction or RhoC regulate Ras/Erk1/2 and FAK/Pyk2 activation through Src. (a) Cav1 controls Src activity. Src activation (Src phosphorylated at Y416) is severely impaired upon loss of Cav1 expression while the total level of Src is not affected. (b) RhoC is involved in Src activation. Src activation was assessed by IB in extracts of F10 and PyMT cells stably expressing siRhoC or shRhoC. (c) Cav1-Rho-GTPase interaction or RhoC control Src, FAK and Pyk2 activation. Phosphorylated tyrosins of Src, FAK and Pyk2 were detected by IB in extracts of two independent F10 clones stably expressing the CBD ${ }^{\mathrm{wt}}$ and clones of F10 cells stably expressing shRhoC, siRhoC or Src-DNRF. The expression of the CBD ${ }^{\mathrm{wt}}$, the RhoC silencing or the expression of a Src dominant-negative form have all the effect of reducing the activation of Src, FAK and Pyk2. (d) Cav1-Rho-GTPase interaction or RhoC control Erk1/2 activation. Activated Erk1/2 were detected by IB in extracts of two independent clones of F10 cells stably expressing the $\mathrm{CBD}^{\mathrm{wt}}$ and clones of $\mathrm{F} 10$ cells stably expressing shRhoC, siRhoC or Src-DNRF. The expression of the CBD ${ }^{\mathrm{wt}}$, RhoC silencing or the expression of Src-DNRF reduce the activation of Erk1/2. (e) Cav1-Rho-GTPase interaction or RhoC control Ras activation. Active Ras (Ras-GTP) was pulled down with agarose beads GST-RBD-conjugated (RBD: Raf 1-binding domain) from extracts of F10 cells stably expressing the $\mathrm{CBD}^{\mathrm{wt}}$, the $\mathrm{CBD}^{\mathrm{mut}}$ or shRhoC. Ras was detected by IB. Either the expression of the CBD or RhoC silencing impairs Ras activation when compared with the expression of the CBD ${ }^{\text {mut }}$. (f) Fluorescence-activated cell sorting analysis of $\alpha 5$-integrin expression. The graphs are representative of three independent experiments. The expression of $\alpha 5$-integrin of F10 cells expressing the $\mathrm{CBD}^{\mathrm{wt}}$ or shRhoC is drastically reduced in comparison with cells expressing the CBD ${ }^{\mathrm{mut}}$. The silencing of RhoA has a minimal effect on $\alpha 5$-integrin expression. (g) Cav1-Rho-GTPase interaction or RhoC control $\alpha 5$-integrin expression. The mRNA expression levels of RhoA, RhoC and $\alpha 5$-integrin were assessed by quantitative reverse transcriptase-PCR. The expression of the $\mathrm{CBD}^{\mathrm{wt}}$ decreases $\alpha 5$-integrin mRNA level without affecting RhoC expression. RhoC silencing also decreases $\alpha 5$-integrin mRNA level. RhoA silencing has a minimal effect on $\alpha 5$-integrin mRNA level, $* * *=$ statistically significant (two-tailed $t$-test with s.e.m.), $P<0.001$. 
a
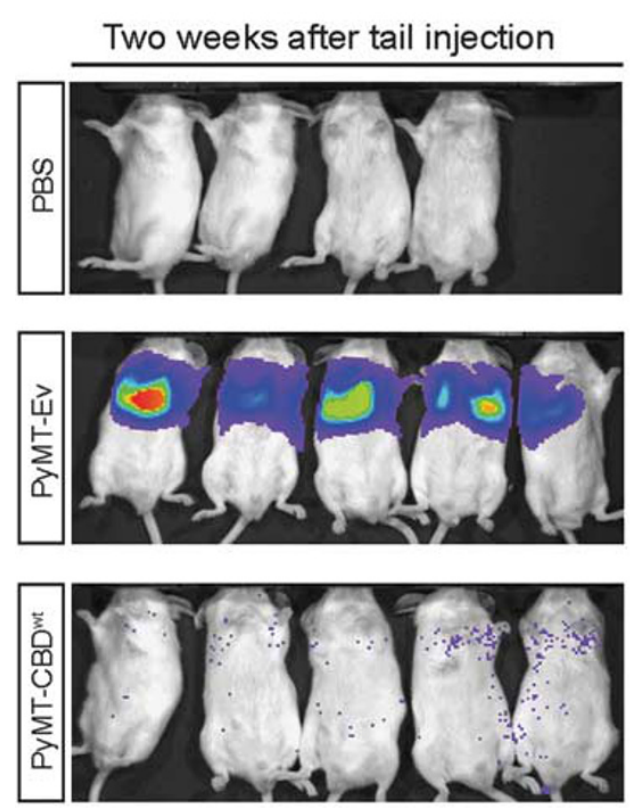
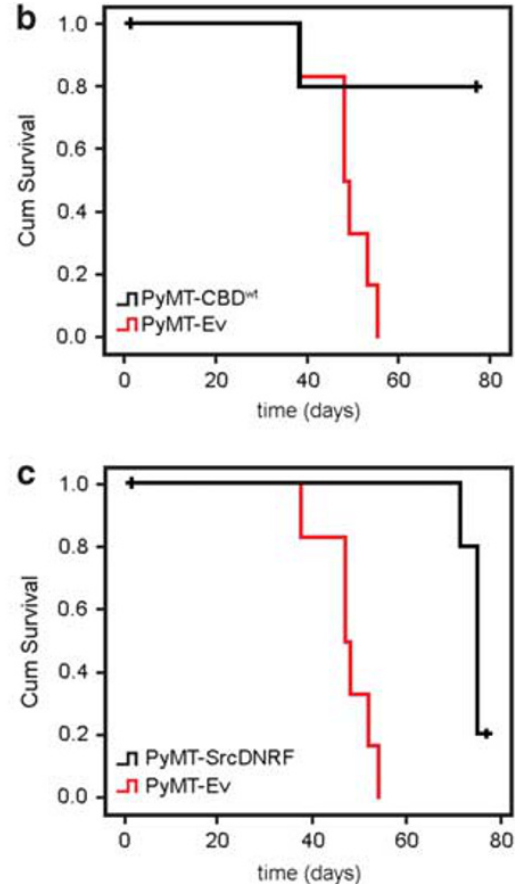

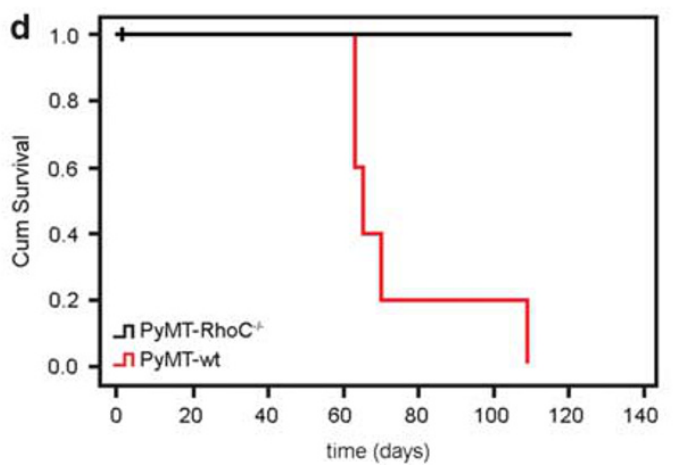

Figure 5 Disruption of the Cavl-Rho-GTPase interaction in PyMT tumor cells: in vivo effects. (a) Less metastasis by CBD ${ }^{\mathrm{wt}}$ expression. SCID mice were tail-vein injected with PBS alone (top panel), PyMT-Ev cells (middle panel) or PyMT-CBD ${ }^{\text {wt }}$ cells (bottom panel). Mice were imaged at 2 weeks post-injection using Xenogen. (b, c) Increased survival of mice bearing tumor cells expressing $\mathrm{CBD}^{\text {wt }}$ or SrcDNRF. Kaplan-Meier survival plots for SCID mice tail-vein injected with PyMT-Ev, PyMT-CBD ${ }^{\text {wt }}$ or PyMT-SrcDNRF cells. Median overall survival: PyMT-Ev, 47 days $\left(n=6\right.$ mice); PyMT-CBD ${ }^{\mathrm{wt}}$, not reached at 84 days $(n=6$ mice). Log-rank test, $P=0.021$. PyMT-SrcDNRF, 76 days $(n=6$ mice). Log-rank test, $P<0.001$. (d) Kaplan-Meier survival plots for $129 \mathrm{P} 2$ mice tailinjected with PyMT-wt or PyMT-RhoC $\mathrm{C}^{-/-}$cells. Median overall survival: PyMT-wt, 65 days $\left(n=5\right.$ mice), PyMT-RhoC $\mathrm{C}^{-/-}$not reached.

than controls, as judged by mouse survival (Figure 5c). Remarkably, the injection of RhoC null PyMT cells (PyMT-RhoC ${ }^{-/-}$cells; Hakem et al., 2005) did not show detectable metastasis or caused the death of any experimental animal (Figure 5d and data not shown). These in vivo results suggest that disruption of Cav1-RhoGTPase interaction, and/or the inhibition of Src, Ras and Erk $1 / 2$ activation that stems from it, can reduce the metastatic potential of cancer cells.

\section{Disruption of Cav-Rho-GTPase interaction impairs} cancer cell extravasation and survival in vivo

The reduced metastasis of $\mathrm{CBD}^{\mathrm{wt}}$-expressing cells could be due to either a decreased capacity of these cells to extravasate or a compromised ability to engraft and survive in a secondary site. To distinguish between these possibilities in vivo, we examined the behavior of F10 cells injected into chicken embryos. We generated F10CBD ${ }^{\mathrm{wt}}$ cells expressing GFP (F10CBD ${ }^{\mathrm{wt}}$ GFP cells), and control F10 cells expressing Ev and the fluorescent protein tomato (F10Ev-tomato cells). The engraftment capacity of these cells was then assessed by injecting them into a vein in the chorioallantoic membrane of the chicken embryo. Quantitative alu PCR was used to determine the number of mouse tumor cells migrating to the lungs and liver (Zijlstra et al., 2002, 2008). At 5 days post-injection, the metastatic load in the lung (Figures $6 \mathrm{a}$ and $\mathrm{b}$ ) and liver (Figures $6 \mathrm{c}$ and $\mathrm{d}$ ) attributable to F10CBD ${ }^{\text {wt }}$ GFP cells was about fourfold lower than the metastatic load associated with F10Ev-tomato cells. Thus, cells lacking Cav1-Rho-GTPase interaction have 

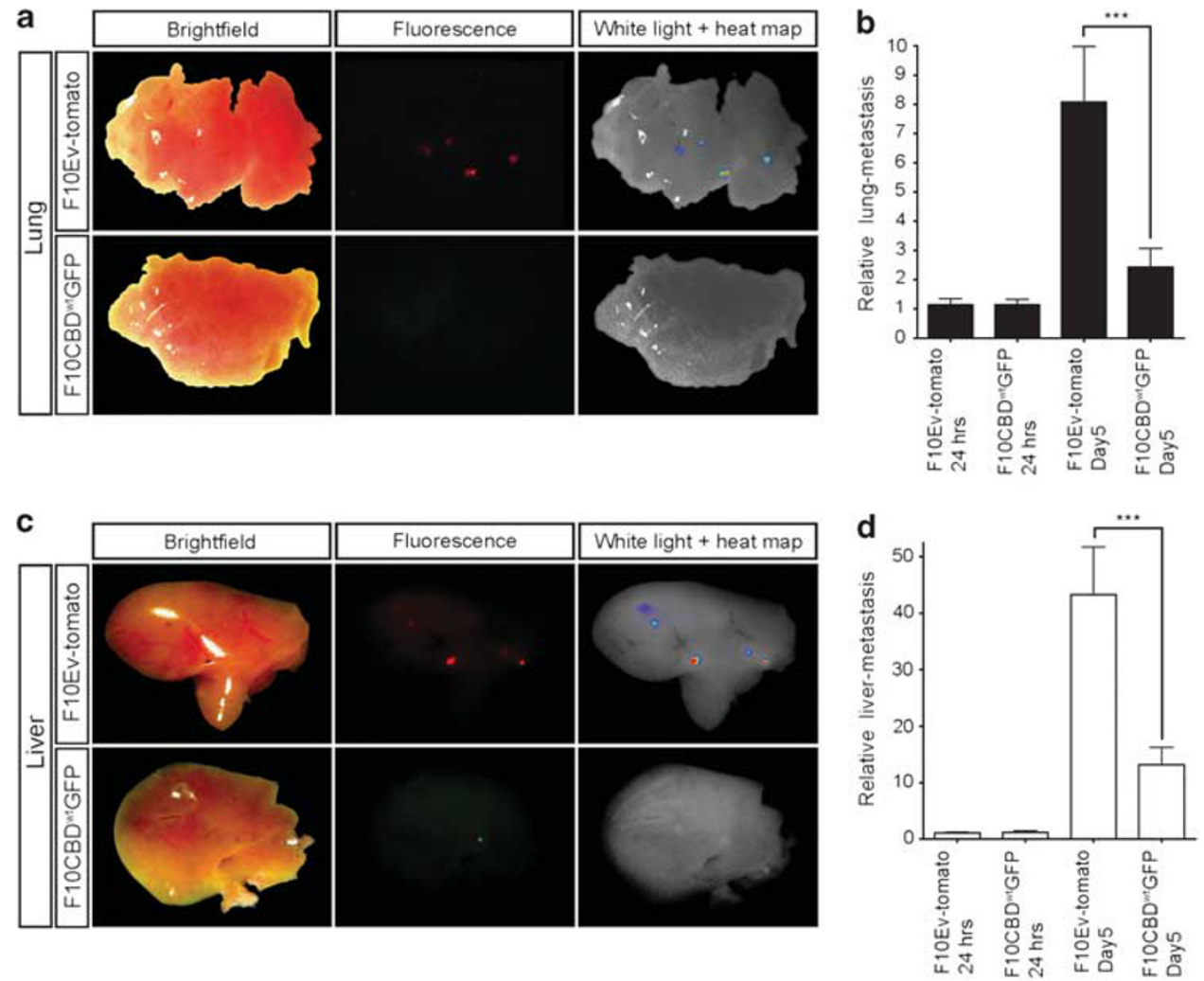

Figure 6 Disruption of the Cav1-Rho-GTPase interaction reduces metastasis in chicken embryos. F10Ev-tomato and F10CBD ${ }^{\text {wt }}$ GFP cells were injected intravenously into the chorioallantoic membrane of chicken embryos and the metastatic spread of these cells to the lungs (a, b) and liver (c, d) was assessed at $24 \mathrm{~h}$ and 5 days post-injection. (a, c) Imaging of dissected lungs and liver of chicken embryos injected with F10Ev-tomato (top) or F10CBD ${ }^{\text {wt }}$ GFP cells (bottom), showing brightfield, fluorescence and overlay images at 5 days post-injection. (b, d) Quantitation of metastases in lungs (b) and liver (d) at $24 \mathrm{~h}$ and 5 days post-injection was performed using quantitative alu PCR, $* * *=$ statistically significant (two-tailed $t$-test with s.e.m.), $P<0.001$.

a diminished ability to engraft not only in mice but also in chicken embryos.

Next, we used intravital imaging to compare the extravasation of $\mathrm{F}_{10 \mathrm{CBD}^{\mathrm{wt}} \mathrm{GFP}}$ and F10Ev-tomato cells. This technique allows the visualization of tumor cells within blood vessels (Lewis et al., 2006), as they are extravasating, and after they have successfully extravasated into the surrounding stroma. Although the extravasation rate of $\mathrm{F} 10 \mathrm{CBD}{ }^{\mathrm{wt}} \mathrm{GFP}$ cells was similar to that of F10Ev-tomato cells (Figure 7a), the attrition rate of $\mathrm{F} 10 \mathrm{CBD}^{\mathrm{wt}} \mathrm{GFP}$ cells during extravasation was double that of F10Ev-tomato cells (Figure 7b). Consequently, fewer F10CBD ${ }^{\mathrm{wt}}$ GFP cells than F10Ev-tomato cells successfully completed extravasation (Supplementary Movies 1,2). This decrease in the viability of F10CBD ${ }^{\text {wt }}$ GFP cells coincided with morphological alterations not seen in F10Ev-tomato cells, either during or after extravasation. Specifically, F10CBD ${ }^{\mathrm{wt}}$ GFPexpressing cells showed a greater number of branched protrusions (Supplementary Figure S4) that may have affected the ability of these cells to extravasate. These data imply that the reduced metastasis that follows $\mathrm{CBD}^{\mathrm{wt}}$ expression may be due in part to detrimental effects on tumor cell survival during extravasation and in the secondary site.

\section{Discussion}

Cav1 and Rho-GTPases have important roles in cell movement, growth, survival, cancer progression and metastasis. Cav1 orchestrates various signaling molecules among Rho-GTPases, which bear a CBD and interact directly with Cav1. Cav1 regulates cell polarization and directional migration through a process involving Src and Rho-GTPases (Grande-Garcia et al., 2007). RhoC contains a putative CBD and interacts directly with Cav1 (Lin et al., 2005). Therefore, the Cav1-Rho-GTPase interaction should be of important biological significance.

We have provided evidence that the expression of the $\mathrm{CBD}^{\mathrm{wt}}$ does not affects $\mathrm{RhoC}$ expression but disrupts the Cav1-Rho-GTPase interaction and compromises cell migration/invasion and survival by altering the expression of $\alpha 5$-integrin, the activity of Src and downstream activation of $\mathrm{p} 130^{\mathrm{Cas}} / \mathrm{Rac} 1, \mathrm{FAK} / \mathrm{Pyk} 2$ and Ras/ Erk1/2. The expression of $\alpha 5$-integrin is virtually absent in $\mathrm{CBD}^{\mathrm{wt}}$-expressing cells or in cells lacking RhoC but it is only marginally affected by RhoA silencing. This argues that the absence of $\alpha 5$-integrin is due to the disrupted interaction of Cav1 and RhoC. At the biochemical level, the expression of the $\mathrm{CBD}^{\mathrm{wt}}$ or the 

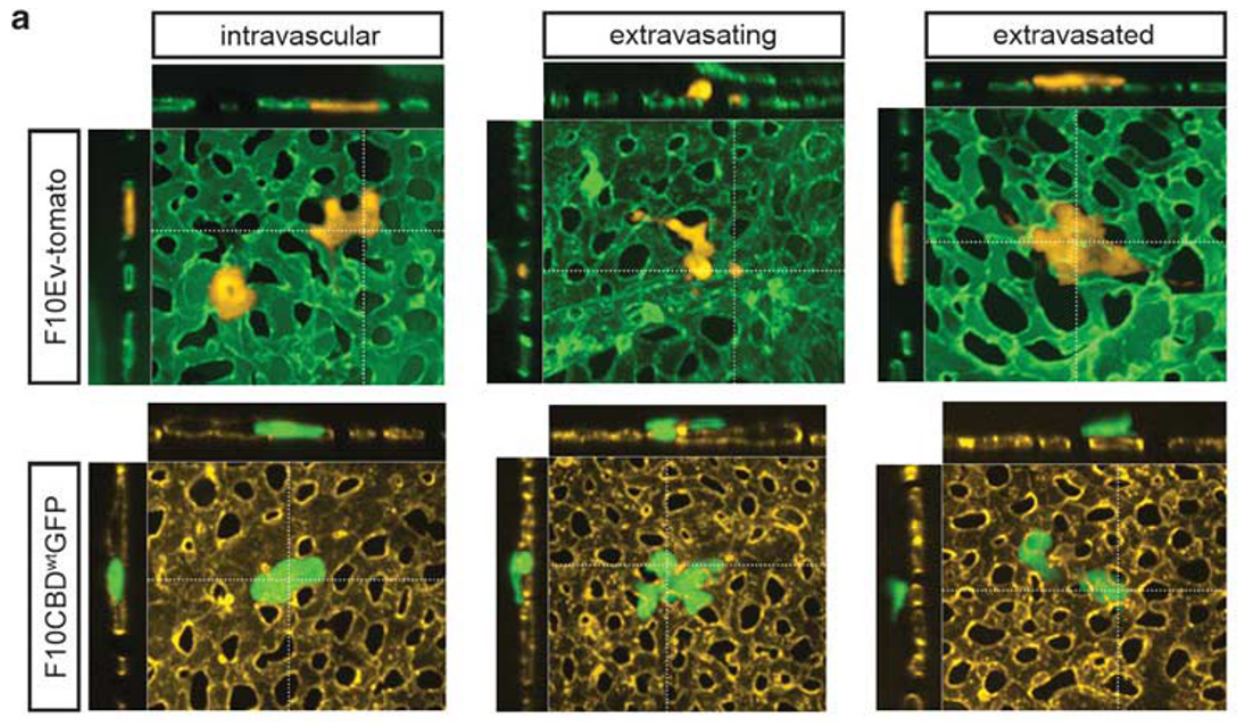

b

Intravascular

Extravasated

Missing/Dead
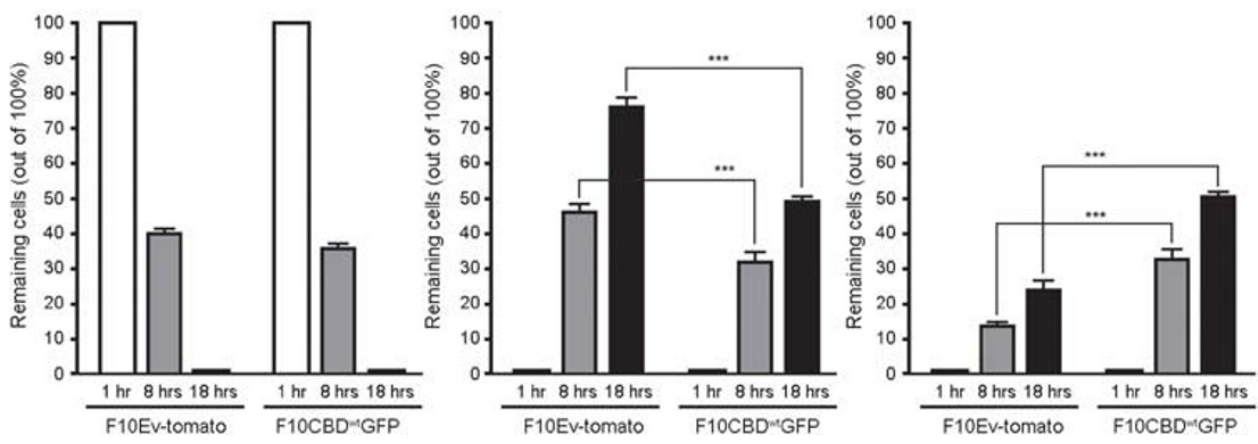

Figure $7 \mathrm{CBD}^{\mathrm{wt}}$ expression interferes with extravasation and cell survival in vivo. F10Ev-tomato and F10CBD ${ }^{\mathrm{wt}} \mathrm{GFP}$ cells were injected intravenously into the chorioallantoic membrane of a chicken embryo and monitored using 3D intravital fluorescence imaging. (a) Imaging. The status of each tumor cell relative to the vasculature was visualized, whether intravascular (left), in the process of extravasating (middle), or extravasated (right). Both F10Ev-tomato and F10CBD ${ }^{\mathrm{wt}} \mathrm{GFP}$ cells were able to extravasate in the CAM. (b) $\mathrm{CBD}^{\mathrm{wt}}$ expression decreases extravasation of tumor cells and profoundly reduces tumor cell survival. The extravasation of individual tumor cells (F10Ev-tomato, $n=1375$ cells; F10CBD ${ }^{\text {wt }} \mathrm{GFP}, n=1365$ cells) was monitored over $18 \mathrm{~h}$. After $1 \mathrm{~h}$, all cells were intravascular. After $8 \mathrm{~h}, 44.9 \%$ more F10Ev-tomato cells had extravasated than F10CBD ${ }^{\mathrm{wt}} \mathrm{GFP}$ cells $(P=0.016)$. After $18 \mathrm{~h}, 54.2 \%$ more F10Ev-tomato cells had extravasated than F10CBD ${ }^{\text {wt }} \mathrm{GFP}$ cells $(P=0.0007),{ }^{* * *}=$ statistically significant (two-tailed $t$-test with s.e.m.), $P<0.001$. This difference in extravasation rate coincides with higher cell death (missing/dead) of F10CBD ${ }^{\mathrm{wt}} \mathrm{GFP}$ cells.

silencing of RhoC has similar effects. Both $\mathrm{CBD}^{\mathrm{wt}}$ expressing cells and cells lacking RhoC exhibit a drastic reduction of Src activity. The reduction of Src activation has several effects. First, Src-dependent p130 ${ }^{\text {Cas }}$ phosphorylation is reduced causing the consequent drastic decrement of Racl activation. Racl has been shown to be a crucial mediator of Src-dependent actin cytoskeleton organization and cell migration (Timpson et al., 2001; Bosco et al., 2009). The observed changes on p130 Cas/Rac1 activation and altered actin cytoskeleton by $\mathrm{CBD}^{\mathrm{wt}}$-expressing cells do explain the migration/ invasion defects observed in vitro. Also, Src-dependent activation of FAK and Pyk2 is affected by $\mathrm{CBD}^{\mathrm{wt}}$ expression or lack of RhoC. In addition to their known involvement in cell adhesion (Schaller 2010), FAK and Pyk2 have been shown to support cell proliferation in a p53-dependent manner (Lim et al., 2008, 2010). Therefore, CBD ${ }^{\mathrm{wt}}$-expressing and RhoC knockdown cells lack survival signals provided by either FAK or Pyk2.

The activation of Ras and Erk1/2 is also impaired in both $\mathrm{CBD}^{\mathrm{wt}}$-expressing cells and cells lacking RhoC. This is consistent with the notion that the Src kinase family can affect cell proliferation via the Ras/ERK/ mitogen-activated protein kinase pathway (Minden et al., 1995; Kim et al., 2009). Moreover, Ras and Erk1/2 have been shown to be involved in cell migration, proliferation and survival (Giehl 2005; Torii et al., 2006). We show for the first time that Ras and Erk $1 / 2$ activation as well as $\alpha 5$-integrin expression might be entirely dependent on RhoC signaling in B16 melanoma cells. Mechanistically, RhoC signaling might affect $\alpha 5$-integrin expression first and that this event, in turn, activates the $\mathrm{Src} / \mathrm{p} 130^{\mathrm{Cas}} / \mathrm{Rac} 1$ signaling cascade. Rho-GTPases are important for integrin clustering/ function (Keely et al., 1998), because the prevention 
of plasma membrane localization of Rho-GTPases decreases $\alpha 5$-integrin mRNA and protein expression (Kidera et al., 2010). On the other hand, Ras can activate integrin signaling although integrin expression is not controlled directly by Ras (Kinbara et al., 2003). The importance of $\alpha 5$-integrin in cell survival/ apoptosis becomes evident when considering that high $\alpha 5$-integrin expression is detrimental for breast cancer patients (Nam et al., 2010). Moreover, various other cancer cell types depend on $\alpha 5$-integrin expression/ function for their survival (O'Brien et al., 1996; Qian et al., 2005; Haenssen et al., 2010). Besides, block of $\alpha 5$-integrin expression/function has been shown to decrease the invasiveness and adhesiveness of cancer cells (Mierke et al., 2011).

We demonstrate that mice or chicken embryos injected with $\mathrm{CBD}^{\mathrm{wt}}$-expressing melanoma cells show great reduction of metastatic burden. The effects of the $\mathrm{CBD}^{\mathrm{wt}}$-expression were not limited to melanoma cells because PyMT mammary gland tumor cells were similarly affected in vivo. Intravital microscopy revealed that $\mathrm{CBD}^{\mathrm{wt}}$-expressing cells encounter problems during extravasation and also display markedly reduced ability to survive post extravasation. We provide the first evidence that the Cavl-Rho-GTPase interaction is important for melanoma cells to extravasate and survive in vivo.

In conclusion, the disruption of the Cav1-RhoGTPase interaction and the absence of RhoC have the same biochemical/phenotypic effects, therefore we speculate that $\mathrm{RhoC}$ is responsible for the metastatic properties of B16 melanoma cells. We suggest that Cav1-RhoC interaction and downstream signaling controls $\alpha 5$-integrin expression. Subsequently, $\alpha 5$-integrin signaling activates the $\mathrm{Src} / \mathrm{FAK} / \mathrm{p} 130^{\text {Cas }}$ pathway (Wu et al., 2008) that leads to Rac1 and Ras/Erk1/2 activation, which altogether is crucial for the migration/ invasion and survival of metastatic melanoma cells.

\section{Materials and methods}

Additional details of material and methods can be found in Supplementary Information.

\section{Plasmids}

Plasmids containing the wild-type and mutant forms of CBD were created by ligating synthetic duplex oligonucleotides into the BamHI/EcoRI sites of pcDNA3.1. The G418- or hygromycin-resistant versions of pcDNA3.1 were used for all cloning. SrcDNRF construct (Millipore, Billerica, MA, USA; Cat\#21-154).

\section{Cancer cell lines and transfections}

B16 F0, F1 and F10 melanoma cells were purchased from American Type Culture Collection (ATCC, Manassas, VA, USA) and maintained in Iscove's modified Dulbecco's media containing 10\% fetal bovine serum. B16 F10 cells expressing luciferase were purchased from Caliper LifeSciences (Corporate Headquarters), Hopkinton, MA, USA). PyMT primary mammary tumor cells were derived in-house from MMTV-PyMT mice. Mammary tumor cells were cultured in
Dulbecco's modified Eagle's medium/HAM-F12 (1:1) media containing $10 \%$ fetal bovine serum, $0.5 \mu \mathrm{g} / \mathrm{ml}$ hydrocortisone (Sigma-Aldrich, St Louis, MO, USA), $5 \mu \mathrm{g} / \mathrm{ml}$ insulin (US Biological, Marblehead, MA, USA) and $5 \mathrm{ng} / \mathrm{ml}$ epidermal growth factor (US Biological) under standard conditions $\left(37^{\circ} \mathrm{C}, 5 \% \mathrm{CO}_{2}\right)$ until spontaneous immortalization occurred. Tumor cells were transfected with plasmids using a standard lipofectamine transfection procedure (Invitrogen Canada, Burlington, ON, Canada) and the desired clones were isolated by selection in the appropriate agents/antibiotics.

\section{$R N A$ interference-mediated gene silencing}

For transient silencing, cells were transfected with 200 pmoles siRNA (either control scrambled siRNA or siRNA against RhoC from Ambion, Applied Biosystems, Carlsbad, CA, USA) using Lipofectamine2000 (Invitrogen) according to the manufacturer's protocol. siRNA sequences are listed in Supplementary Information. Transfected cells were analyzed by immunoblotting at $72 \mathrm{~h}$ post-transfection as described below. For stable knockdowns, control siRNA and short hairpin RNA against RhoC, Cav1, RhoA were either cloned into the pSilencer vector (Ambion) or were purchased ready for lentiviral expression (Open Biosystems Products, Huntsville, AL, USA; Sigma-Aldrich). Lentiviral particles were produced in 293FT cells and virus-containing culture supernatants were used to infect cells in the presence of $8 \mu \mathrm{g} / \mathrm{ml}$ polybrene (Sigma).

\section{Immunoblotting}

Extracts of transfected or transduced cells were prepared in RIPA buffer. Equal amounts of protein were resolved by sodium dodecyl sulfate-polyacrylamide gel electrophoresis and subjected to immunoblotting using the following antibodies: rabbit polyclonal anti-Cav1 (Santa-Cruz Biotechnology, Inc., Santa Cruz, CA, USA); rabbit polyclonal anti-p130 Cas (Sigma); rabbit polyclonal antibodies specific for the Y165 or Y410 phosphorylated forms of $130^{\text {Cas }}$, or phosphorylated Src-Y416 (Cell Signaling Technology, Inc., Danvers, MA, USA), rabbit polyclonal antibodies specific for FAK-Y925, Pyk2-Y402, total Erk1/2; or phosphorylated forms of Erk1/2-T202/Y204 (Cell Signaling). To detect Cav1 bound to Rho-GTPases in the presence of the $\mathrm{CBD}^{\mathrm{wt}}$ and $\mathrm{CBD}^{\mathrm{mut}}$, immunoblotting of immunoprecipitates obtained using the Rho activation kit (Millipore) was performed using anti-Cav1 antibody as above. Anti-Rho (-A, -B, -C) antibody, clone 55 (Millipore), antiRac1 mouse monoclonal antibody (Cytoskeleton Inc., Denver, CO, USA) and anti-Ras monoclonal antibody clone RAS10 (Millipore).

\section{Transwell migration/invasion and wound-healing assays}

For Transwell migration/invasion, cells $\left(1 \times 10^{5}\right)$ that had been cultured overnight in media containing $0.2 \%$. Fetal bovine serum was plated into the upper chamber of a Transwell insert $(8 \mu \mathrm{m}$ pore size) that had been coated with collagen-IV for migration assays, or with Matrigel for invasion assays (BD - Canada, Mississauga, ON, Canada). The upper and lower chambers were then filled with medium containing $5 \%$ fetal bovine serum and the cells were cultured for $24 \mathrm{~h}$ under standard conditions. For visualization, cells were fixed and stained with $1 \%$ methylene blue in $50 \%$ methanol. For the wound-healing assay, cell cultures at near-confluence were wounded by creating a 'scratch' in the cell monolayer. At $48 \mathrm{~h}$ post-wounding, cell migration was examined after cell cultures were fixed by staining with $1 \%$ methylene blue in $50 \%$ methanol 
Cells $\left(5 \times 10^{6}\right)$ were serum-starved overnight before stimulation for $15 \mathrm{~min}$ with $50 \mathrm{ng} / \mathrm{ml}$ insulin-like growth factor (IGF; US Biologicals) for Rho-GTPase and Ras activation, or for $5 \mathrm{~min}$ with $10 \mathrm{ng} / \mathrm{ml}$ insulin-like growth factor for Rac1 activation. Specific activation of GTP-loaded Rho-GTPases, Racl or Ras was detected using the Rho activation kit (Millipore), the Rac1 activation kit (Cytoskeleton Inc.) or the Ras activation kit (Millipore), respectively, according to each manufacturer's protocol.

\section{Actin visualization}

Cells $\left(2 \times 10^{4}\right)$ were plated on uncoated $12 \mathrm{~mm}$ glass coverslips and allowed to attach overnight before fixation in $2 \%$ formaldehyde/phosphate-buffered saline (PBS) and permeabilization in $0.5 \%$ Triton-X-100/PBS. Permeabilized cells were washed in PBS and actin was detected by rhodaminephalloidin (PHDR1; Cytoskeleton Inc.). Fluorescent images were obtained using an Olympus-Fluoview-FV1000 confocal microscope (Olympus Canada Inc., Markham, ON, Canada).

\section{Integrin assays and quantitative reverse transcriptase-PCR}

The expression of $\alpha 5$-integrin was assessed by fluorescenceactivated cell sorting analysis on a BD FACSCanto II flow cytometer. Cells $\left(10^{6}\right)$ were stained with anti-CD49e ( $\alpha 5$-integrin) antibody BD clone $5 \mathrm{H} 10-27$.

The mRNA level was assessed by quantitative reverse transcriptase-PCR. TRIzol reagent (Invitrogen) was used for RNA extraction and the iScript reverse transcription-kit (Bio-Rad Laboratories (Canada) Ltd., Mississauga, ON, Canada) to produce complementary DNA. The quantitative reverse transcriptase-PCR reaction was performed using SYBR Green (Applied Biosystems, Carlsbad, CA, USA) and the Applied Biosystems Real-time PCR-7900HT. The gapdh gene amplification was used as internal reference.

\section{In vivo analyses of metastasis in mice}

Tumor cells $\left(5 \times 10^{5}\right.$ in $100 \mu \mathrm{l}$ PBS $)$ were injected into the tail-vein of C57/B6 or SCID mice. In situ imaging of luciferaseexpressing metastatic cells was performed using a Xenogen apparatus (IVIS Imaging Systems, Caliper LifeSciences). Mouse survival over 60-80 days was evaluated using Kaplan-Meier methodology. All animal experiments were approved by the Animal Care and Use Committee of the University Health Network (Toronto, Canada).

Quantitation of in vivo metastasis in chicken embryos Fertilized chicken eggs were incubated in a rotary incubator at $37^{\circ} \mathrm{C}$ with $70 \%$ humidity for 4 days before being removed from the shell and placed in covered dishes. On day 12 of development, $2 \times 10^{5}$ tumor cells in $50 \mu \mathrm{l}$ PBS were injected into a vein within the chorioallantoic membrane. Chicken embryonic liver and lung were harvested at $24 \mathrm{~h}$ and 5 days post-injection and mouse tumor cells in these organs were measured using quantitative PCR to detect the mouse alu sequence. The cT values obtained from the mouse alu amplification were normalized to the chicken GAPDH as previously described (Zijlstra et al., 2002, 2008).

Intravital imaging of tumor cell migration and extravasation Real-time imaging of the intravascular migration and extravasation of mouse tumor cells in chicken embryos was performed using a chicken embryo imaging unit as previously described (Zijlstra et al., 2008). Briefly, the embryonic chicken vasculature was labeled with fluorescent Lens Culinaris Agglutinin (LCA, Vector Laboratories, Burlingame, CA, USA). F10CBD ${ }^{\text {wt }}$ GFP or F10Ev-tomato cells $\left(2 \times 10^{5}\right)$ were injected into a vein within the chorioallantoic membraneand the embryos were visualized using a spinning-disk confocal microscope (Quorum Technologies, Waterloo, ON, Canada).

\section{Statistics}

Kaplan-Meier survival plots and intergroup comparison statistics were determined by using GraphPad PRISM-5 software (GraphPad Software, Inc., La Jolla, CA, USA) The log-rank test was used to evaluate differences in animal survival among experimental groups ( $P$-value). The two-tailed $t$-test with s.e.m. was used to evaluate differences in tumor cell extravasation and survival in chicken embryos.

\section{Conflict of interest}

The authors declare no conflict of interest.

\section{Acknowledgements}

We thank Dr Marc Pellegrini for helpful discussions and Dr Mary Saunders for insightful scientific editing. This work was supported by Grant \#179815 from the Canadian Institutes of Health Research to TWM, and Grant \#18176 from the National Cancer Institute of Canada/Terry Fox Foundation to JDL. HSL is funded by a Canadian Breast Cancer Foundation Post-Doctoral fellowship.

\section{References}

Bonni A, Brunet A, West AE, Datta SR, Takasu MA, Greenberg ME. (1999). Cell survival promoted by the Ras-MAPK signaling pathway by transcription-dependent and -independent mechanisms. Science 286: 1358-1362.

Bosco EE, Mulloy JC, Zheng Y. (2009). Racl GTPase: a 'Rac' of all trades. Cell Mol Life Sci 66: 370-374.

Brabek J, Constancio SS, Siesser PF, Shin NY, Pozzi A, Hanks SK. (2005). Crk-associated substrate tyrosine phosphorylation sites are critical for invasion and metastasis of SRC-transformed cells. Mol Cancer Res 3: 307-315.

Campbell L, Jasani B, Edwards K, Gumbleton M, Griffiths DF. (2008). Combined expression of caveolin-1 and an activated AKT/
mTOR pathway predicts reduced disease-free survival in clinically confined renal cell carcinoma. Br J Cancer 98: 931-940.

Capozza F, Williams TM, Schubert W, McClain S, Bouzahzah B, Sotgia F et al. (2003). Absence of caveolin-1 sensitizes mouse skin to carcinogen-induced epidermal hyperplasia and tumor formation. Am J Pathol 162: 2029-2039.

Clark EA, Golub TR, Lander ES, Hynes RO. (2000). Genomic analysis of metastasis reveals an essential role for RhoC. Nature 406: 532-535.

Cokakli M, Erdal E, Nart D, Yilmaz F, Sagol O, Kilic M et al. (2009). Differential expression of caveolin-1 in hepatocellular carcinoma: correlation with differentiation state, motility and invasion. BMC Cancer 9: 65. 
Couet J, Belanger MM, Roussel E, Drolet MC. (2001). Cell biology of caveolae and caveolin. Adv Drug Deliv Rev 49: 223-235.

Couet J, Li S, Okamoto T, Ikezu T, Lisanti MP. (1997). Identification of peptide and protein ligands for the caveolin-scaffolding domain. Implications for the interaction of caveolin with caveolae-associated proteins. J Biol Chem 272: 6525-6533.

Dent P, Reardon DB, Park JS, Bowers G, Logsdon C, Valerie K et al. (1999). Radiation-induced release of transforming growth factor alpha activates the epidermal growth factor receptor and mitogenactivated protein kinase pathway in carcinoma cells, leading to increased proliferation and protection from radiation-induced cell death. Mol Biol Cell 10: 2493-2506.

Fecchi K, Travaglione S, Spadaro F, Quattrini A, Parolini I, Piccaro G et al. (2011). Human melanoma cells express FGFR/Src/Rho signaling that entails an adhesion-independent caveolin-1 membrane association. Int J Cancer (doi:10.1002/ijc.26092).

Felicetti F, Parolini I, Bottero L, Fecchi K, Errico MC, Raggi C et al. (2009). Caveolin-1 tumor-promoting role in human melanoma. Int $J$ Cancer 125: 1514-1522.

Fincham VJ, Unlu M, Brunton VG, Pitts JD, Wyke JA, Frame MC (1996). Translocation of Src kinase to the cell periphery is mediated by the actin cytoskeleton under the control of the Rho family of small G proteins. $J$ Cell Biol 135: 1551-1564.

Gardner AM, Vaillancourt RR, Johnson GL. (1993). Activation of mitogen-activated protein kinase/extracellular signal-regulated kinase kinase by $\mathrm{G}$ protein and tyrosine kinase oncoproteins. $J$ Biol Chem 268: 17896-17901.

Giehl K. (2005). Oncogenic Ras in tumour progression and metastasis. Biol Chem 386: 193-205.

Goetz JG, Joshi B, Lajoie P, Strugnell SS, Scudamore T, Kojic LD et al. (2008). Concerted regulation of focal adhesion dynamics by galectin-3 and tyrosine-phosphorylated caveolin-1. J Cell Biol $\mathbf{1 8 0}$ 1261-1275.

Grande-Garcia A, Echarri A, de Rooij J, Alderson NB, WatermanStorer CM, Valdivielso JM et al. (2007). Caveolin-1 regulates cell polarization and directional migration through Src kinase and Rho GTPases. $J$ Cell Biol 177: 683-694.

Haenssen KK, Caldwell SA, Shahriari KS, Jackson SR, Whelan KA, Klein-Szanto AJ et al. (2010). ErbB2 requires integrin alpha5 for anoikis resistance via Src regulation of receptor activity in human mammary epithelial cells. J Cell Sci 123: 1373-1382.

Hakem A, Sanchez-Sweatman O, You-Ten A, Duncan G, Wakeham A, Khokha $\mathrm{R}$ et al. (2005). RhoC is dispensable for embryogenesis and tumor initiation but essential for metastasis. Genes Dev 19: 1974-1979.

Hall A. (1998). Rho GTPases and the actin cytoskeleton. Science 279: $509-514$.

Heasman SJ, Ridley AJ. (2008). Mammalian Rho GTPases: new insights into their functions from in vivo studies. Nat Rev Mol Cell Biol 9: 690-701.

Ho CC, Huang PH, Huang HY, Chen YH, Yang PC, Hsu SM. (2002). Up-regulated caveolin-1 accentuates the metastasis capability of lung adenocarcinoma by inducing filopodia formation. Am J Pathol 161: $1647-1656$

Ilic D, Furuta Y, Kanazawa S, Takeda N, Sobue K, Nakatsuji N et al. (1995). Reduced cell motility and enhanced focal adhesion contact formation in cells from FAK-deficient mice. Nature $\mathbf{3 7 7}$ $539-544$.

Jaffe AB, Hall A. (2002). Rho GTPases in transformation and metastasis. Adv Cancer Res 84: 57-80.

Keely P, Parise L, Juliano R. (1998). Integrins and GTPases in tumour cell growth, motility and invasion. Trends Cell Biol 8: 101-106.

Kidera Y, Tsubaki M, Yamazoe Y, Shoji K, Nakamura H, Ogaki M et al. (2010). Reduction of lung metastasis, cell invasion, and adhesion in mouse melanoma by statin-induced blockade of the Rho/Rho-associated coiled-coil-containing protein kinase pathway. J Exp Clin Cancer Res 29: 127.

Kim LC, Song L, Haura EB. (2009). Src kinases as therapeutic targets for cancer. Nat Rev Clin Oncol 6: 587-595.
Kinbara K, Goldfinger LE, Hansen M, Chou FL, Ginsberg MH. (2003). Ras GTPases: integrins' friends or foes? Nat Rev Mol Cell Biol 4: 767-776.

Klemke RL, Leng J, Molander R, Brooks PC, Vuori K, Cheresh DA. (1998). CAS/Crk coupling serves as a 'molecular switch' for induction of cell migration. $J$ Cell Biol 140: 961-972.

Krueger JS, Keshamouni VG, Atanaskova N, Reddy KB. (2001). Temporal and quantitative regulation of mitogen-activated protein kinase (MAPK) modulates cell motility and invasion. Oncogene 20: 4209-4218.

Lewis JD, Destito G, Zijlstra A, Gonzalez MJ, Quigley JP, Manchester $\mathrm{M}$ et al. (2006). Viral nanoparticles as tools for intravital vascular imaging. Nat Med 12: 354-360

Li L, Yang G, Ebara S, Satoh T, Nasu Y, Timme TL et al. (2001). Caveolin-1 mediates testosterone-stimulated survival/clonal growth and promotes metastatic activities in prostate cancer cells. Cancer Res 61: 4386-4392.

Lim ST, Chen XL, Lim Y, Hanson DA, Vo TT, Howerton K et al. (2008). Nuclear FAK promotes cell proliferation and survival through FERM-enhanced p53 degradation. Mol Cell 29: 9-22.

Lim ST, Miller NL, Nam JO, Chen XL, Lim Y, Schlaepfer DD. (2010). Pyk2 inhibition of p53 as an adaptive and intrinsic mechanism facilitating cell proliferation and survival. $J$ Biol Chem 285: 1743-1753.

Lin M, DiVito MM, Merajver SD, Boyanapalli M, van Golen KL. (2005). Regulation of pancreatic cancer cell migration and invasion by RhoC GTPase and caveolin-1. Mol Cancer 4: 21.

Marti A, Luo Z, Cunningham C, Ohta Y, Hartwig J, Stossel TP et al. (1997). Actin-binding protein-280 binds the stress-activated protein kinase (SAPK) activator SEK-1 and is required for tumor necrosis factor-alpha activation of SAPK in melanoma cells. $J$ Biol Chem 272: $2620-2628$

Mebratu Y, Tesfaigzi Y. (2009). How ERK1/2 activation controls cell proliferation and cell death: Is subcellular localization the answer? Cell Cycle 8: 1168-1175.

Meenderink LM, Ryzhova LM, Donato DM, Gochberg DF, Kaverina I, Hanks SK. (2010). P130Cas Src-binding and substrate domains have distinct roles in sustaining focal adhesion disassembly and promoting cell migration. PLoS One 5: e13412.

Mierke CT, Frey B, Fellner M, Herrmann M, Fabry B. (2011). Integrin alpha5betal facilitates cancer cell invasion through enhanced contractile forces. $J$ Cell Sci 124: 369-383.

Minden A, Lin A, Claret FX, Abo A, Karin M. (1995). Selective activation of the JNK signaling cascade and c-Jun transcriptional activity by the small GTPases Rac and Cdc42Hs. Cell 81: 1147-1157.

Nam JM, Onodera Y, Bissell MJ, Park CC. (2010). Breast cancer cells in three-dimensional culture display an enhanced radioresponse after coordinate targeting of integrin alpha5betal and fibronectin. Cancer Res 70: 5238-5248.

Narumiya S, Tanji M, Ishizaki T. (2009). Rho signaling, ROCK and mDial, in transformation, metastasis and invasion. Cancer Metastasis Rev 28: 65-76.

Natali PG, Nicotra MR, Di Filippo F, Bigotti A. (1995). Expression of fibronectin, fibronectin isoforms and integrin receptors in melanocytic lesions. Br J Cancer 71: 1243-1247.

O'Brien V, Frisch SM, Juliano RL. (1996). Expression of the integrin alpha 5 subunit in HT29 colon carcinoma cells suppresses apoptosis triggered by serum deprivation. Exp Cell Res 224: 208-213.

Ohta Y, Suzuki N, Nakamura S, Hartwig JH, Stossel TP. (1999). The small GTPase RalA targets filamin to induce filopodia. Proc Natl Acad Sci U S A 96: 2122-2128.

Qian F, Zhang ZC, Wu XF, Li YP, Xu Q. (2005). Interaction between integrin alpha(5) and fibronectin is required for metastasis of B16F10 melanoma cells. Biochem Biophys Res Commun 333: $1269-1275$.

Quest AF, Gutierrez-Pajares JL, Torres VA. (2008). Caveolin-1: an ambiguous partner in cell signalling and cancer. J Cell Mol Med 12: $1130-1150$.

Sahai E, Marshall CJ. (2002). RHO-GTPases and cancer. Nat Rev Cancer 2: 133-142. 
Sakai R, Iwamatsu A, Hirano N, Ogawa S, Tanaka T, Mano H et al. (1994). A novel signaling molecule, p130, forms stable complexes in vivo with $\mathrm{v}-\mathrm{Crk}$ and $\mathrm{v}-\mathrm{Src}$ in a tyrosine phosphorylationdependent manner. EMBO J 13: 3748-3756.

Schaller MD. (2010). Cellular functions of FAK kinases: insight into molecular mechanisms and novel functions. J Cell Sci 123: 1007-1013.

Sharma A, Mayer BJ. (2008). Phosphorylation of p130Cas initiates Rac activation and membrane ruffling. BMC Cell Biol 9: 50.

Shaul YD, Seger R. (2007). The MEK/ERK cascade: from signaling specificity to diverse functions. Biochim Biophys Acta 1773: 1213-1226.

Sieg DJ, Ilic D, Jones KC, Damsky CH, Hunter T, Schlaepfer DD. (1998). Pyk2 and Src-family protein-tyrosine kinases compensate for the loss of FAK in fibronectin-stimulated signaling events but Pyk2 does not fully function to enhance FAK- cell migration. EMBO J 17: 5933-5947.

Smart EJ, Graf GA, McNiven MA, Sessa WC, Engelman JA, Scherer PE et al. (1999). Caveolins, liquid-ordered domains, and signal transduction. Mol Cell Biol 19: 7289-7304.

Thompson TC, Timme TL, Li L, Goltsov A. (1999). Caveolin-1, a metastasis-related gene that promotes cell survival in prostate cancer. Apoptosis 4: 233-237.

Timpson P, Jones GE, Frame MC, Brunton VG. (2001). Coordination of cell polarization and migration by the Rho family GTPases requires Src tyrosine kinase activity. Curr Biol 11: 1836-1846.

Torii S, Yamamoto T, Tsuchiya Y, Nishida E. (2006). ERK MAP kinase in $\mathrm{G}$ cell cycle progression and cancer. Cancer Sci $\mathbf{9 7}$ : 697-702.

Wheeler DL, Iida M, Dunn EF. (2009). The role of Src in solid tumors. Oncologist 14: 667-678.

Williams TM, Cheung MW, Park DS, Razani B, Cohen AW, Muller WJ et al. (2003). Loss of caveolin-1 gene expression accelerates the development of dysplastic mammary lesions in tumor-prone transgenic mice. Mol Biol Cell 14: 1027-1042.

Williams TM, Hassan GS, Li J, Cohen AW, Medina F, Frank PG et al. (2005). Caveolin-1 promotes tumor progression in an autochthonous mouse model of prostate cancer: genetic ablation

of Cav-1 delays advanced prostate tumor development in tramp mice. J Biol Chem 280: 25134-25145.

Williams TM, Medina F, Badano I, Hazan RB, Hutchinson J, Muller WJ et al. (2004). Caveolin-1 gene disruption promotes mammary tumorigenesis and dramatically enhances lung metastasis in vivo. Role of Cav-1 in cell invasiveness and matrix metalloproteinase (MMP-2/9) secretion. J Biol Chem 279: 51630-51646.

Wu L, Bernard-Trifilo JA, Lim Y, Lim ST, Mitra SK, Uryu S et al (2008). Distinct FAK-Src activation events promote alpha5betal and alpha4betal integrin-stimulated neuroblastoma cell motility. Oncogene 27: 1439-1448.

Yamamoto T, Taya S, Kaibuchi K. (1999). Ras-induced transformation and signaling pathway. J Biochem 126: 799-803.

Yamana N, Arakawa Y, Nishino T, Kurokawa K, Tanji M, Itoh RE et al. (2006). The Rho-mDial pathway regulates cell polarity and focal adhesion turnover in migrating cells through mobilizing Apc and c-Src. Mol Cell Biol 26: 6844-6858.

Yip SC, El-Sibai M, Coniglio SJ, Mouneimne G, Eddy RJ, Drees BE et al. (2007). The distinct roles of Ras and Rac in PI 3-kinasedependent protrusion during EGF-stimulated cell migration. $J$ Cell Sci 120: 3138-3146.

Zhang Z, Vuori K, Wang H, Reed JC, Ruoslahti E. (1996). Integrin activation by R-ras. Cell 85: 61-69.

Zijlstra A, Lewis J, Degryse B, Stuhlmann H, Quigley JP. (2008). The inhibition of tumor cell intravasation and subsequent metastasis via regulation of in vivo tumor cell motility by the tetraspanin CD151. Cancer Cell 13: 221-234.

Zijlstra A, Mellor R, Panzarella G, Aimes RT, Hooper JD, Marchenko ND et al. (2002). A quantitative analysis of ratelimiting steps in the metastatic cascade using human-specific realtime polymerase chain reaction. Cancer Res 62: 7083-7092.

\section{(c)}

SOMERIGHTS RESE

This work is licensed under the Creative Commons Attribution-NonCommercial-No Derivative

Works 3.0 Unported License. To view a copy of this license, visit http://creativecommons.org/licenses/by-nc-nd/3.0/

Supplementary Information accompanies the paper on the Oncogene website (http://www.nature.com/onc) 